\title{
Medical Quiz: Single Best Answer (SBA)
}

\author{
Ahmed JU
}

(BIRDEM Med J 2018; 8(1): 84 )

Question No.01

A 68-year-old woman has presented with acute onset shortness of breath 24 hours after a long haul flight. Her blood results show a raised D-dimer level and the arterial blood gas shows a PO2 of $8.3 \mathrm{kPa}$ and $\mathrm{PCO} 2$ of $5.4 \mathrm{kPa}$. You are suspecting pulmonary embolism. Patient is waiting for a CT-Pulmonary angiogram. From the list below, please select the most appropriate treatment measure.
A. Commence loading with warfarin and aim for an INR between 2 and 3
B. Thromboembolic deterrent stockings
C. Aspirin $75 \mathrm{mg}$ daily
D. Prophylactic dose subcutaneous low molecular weight heparin along with loading dose warfarin and aim for INR between 2 and 3
E. Treatment dose subcutaneous low molecular weight heparin along with loading dose warfarin and aim for INR between 2 and 3

\section{Question No. 02}

You see a 47-year-old woman who presents with a 3day history of jaundice. You assess her liver function tests (LFTs) and see that the ALP iu/L is raised at 350 $\mathrm{iu} / \mathrm{L}, \mathrm{AST} 45 \mathrm{iu} / \mathrm{L}$, ALT $50 \mathrm{iu} / \mathrm{L}$ and bilirubin $50 \mathrm{iu} / \mathrm{L}$. The patient feels well in herself, although she has noticed that her urine has become quite dark and her stools quite pale. You assess her medication history. Which of the following drugs from the patient's medication history may be responsible for the cholestasis?
A. Co-amoxiclav
B. Bendroflumethiazide
C. Ramipril
D. Amlodipine
E. Aspirin

Author Information

a. Dr. Jamal Uddin Ahmed, Associate Professor of Medicine, BIRDEM General Hospital

\section{Question No. 03}

A 67-year-old man presented with pain in his pelvis. During the consultation, he mentions that his friends have been commenting that his head appears larger than before. In addition, he has noticed deterioration in hearing in his left ear. On neurological examination, a left-sided sensorineural deafness is detected. Closer inspection of the legs reveals bowing of the tibia. What is the most likely diagnosis?
A. Osteomalacia
B. Osteoporosis
C. Acromegaly
D. Ricketts
E. Paget's disease

\section{Question No. 04}

A 78 year old right-handed male collapses and is brought to the emergency. He seems to follow clear one-step commands but he gets very frustrated as he cannot answer questions. He is unable to lift his right hand or leg. He has an irregularly irregular pulse and his blood pressure is $150 / 90 \mathrm{~mm} \mathrm{Hg}$. He takes only aspirin and frusemide. What is the most likely diagnosis?
A. Left cortical infarct
B. Right internal capsule infarct
C. Left cortical hemorrhage
D. Left internal capsule hemorrhage
E. Brainstem hemorrhage

\section{Question No. 05}

A 62-year-old woman with metastatic breast cancer, including bone metastases, presented with sudden onset back pain and difficulty in walking. An urgent MRI of the spine confirms spinal cord compression at the level of L1-L2. What is the most appropriate initial management?
A. Surgical decompression of spinal cord
B. Dexamethasone
C. Radiotherapy
D. Chemotherapy
E. Physiotherapy 